\title{
Article
}

\section{Influence of excipients on spray-dried powders for inhalation}

Xu, En-Yu, Guo, Jing, Xu, Ying, Li, Hao-Ying and Seville, Peter C.

Available at http://clok.uclan.ac.uk/13610/

Xu, En-Yu, Guo, Jing, Xu, Ying, Li, Hao-Ying and Seville, Peter C. ORCID: 00000001-8546-3474 (2014) Influence of excipients on spray-dried powders for inhalation. Powder Technology, 256 . pp. 217-223. ISSN 00325910

It is advisable to refer to the publisher's version if you intend to cite from the work. http://dx.doi.org/10.1016/j.powtec.2014.02.033

For more information about UCLan's research in this area go to http://www.uclan.ac.uk/researchgroups/ and search for < name of research Group>.

For information about Research generally at UCLan please go to http://www.uclan.ac.uk/research/

All outputs in CLoK are protected by Intellectual Property Rights law, including Copyright law. Copyright, IPR and Moral Rights for the works on this site are retained by the individual authors and/or other copyright owners. Terms and conditions for use of this material are defined in the policies page.

\section{CLoK}

Central Lancashire online Knowledge www.clok.uclan.ac.uk

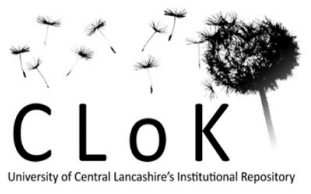




\section{Accepted Manuscript}

Influence of excipients on spray-dried powders for inhalation

En-Yu Xu, Jing Guo, Ying Xu, Hao-Ying Li, Peter C. Seville

PII:

S0032-5910(14)00149-1

DOI:

doi: 10.1016/j.powtec.2014.02.033

Reference:

PTEC 10058

To appear in: $\quad$ Powder Technology

Received date: $\quad 7$ November 2013

Revised date: $\quad 3$ February 2014

Accepted date: 9 February 2014

Please cite this article as: En-Yu Xu, Jing Guo, Ying Xu, Hao-Ying Li, Peter C. Seville, Influence of excipients on spray-dried powders for inhalation, Powder Technology (2014), doi: $10.1016 /$ j.powtec.2014.02.033

This is a PDF file of an unedited manuscript that has been accepted for publication. As a service to our customers we are providing this early version of the manuscript. The manuscript will undergo copyediting, typesetting, and review of the resulting proof before it is published in its final form. Please note that during the production process errors may be discovered which could affect the content, and all legal disclaimers that apply to the journal pertain. 


\title{
Influence of excipients on spray-dried powders for inhalation
}

\author{
En-Yu Xu ${ }^{\mathrm{a}, \mathrm{b}}$, Jing Guo ${ }^{\mathrm{b}}$, Ying $\mathrm{Xu}^{\mathrm{c}}$, Hao-Ying $\mathrm{Li}^{\mathrm{b}}$ and Peter C Seville ${ }^{\mathrm{d}, *}$
}

${ }^{a}$ College of Basic Medical Science, China Medical University, Shen-Yang 110001, China

${ }^{\mathrm{b}}$ Biomanufacturing Research Centre, School of Mechanical and Electrical Engineering, Soochow University, Su-Zhou 215021, China

${ }^{\mathrm{c}}$ Testing and Analysis Centre, Soochow University, Su-Zhou 215123, China

${ }^{\mathrm{d}}$ School of Clinical and Experimental Medicine, College of Medical and Dental Sciences, University of Birmingham, Edgbaston, Birmingham B15 2TT, UK

*Corresponding Author:

Dr Peter Seville

Pharmacy, Pharmacology and Therapeutics Section,

School of Clinical and Experimental Medicine,

College of Medical and Dental Sciences,

University of Birmingham, Edgbaston,

Birmingham B15 2TT, UK

Tel: +44(0)1214143209

Email: p.c.seville@bham.ac.uk 


\begin{abstract}
Two areas attracting considerable attention when developing effective pulmonary drug delivery systems include the improvement of aerosolisation efficiency of the inhaled formulation and the controlled release of drug from the formulation following deposition within the lung. In this study, four saccharides were employed as excipients in the preparation of spray-dried powder formulations for the pulmonary drug delivery. Betacyclodextrin-, starch-, and sodium carboxymethylcellulose (NaCMC)-based spray-dried powders showed a significant (one-way ANOVA, Duncan's test, $p<0.05$ ) increase in lower stage drug deposition in the Next Generation Impactor (NGI) when compared to lactosebased spray-dried powders. Furthermore, NaCMC-based spray-dried powder formulations exhibited a sustained drug release profile in dissolution testing; approximately $80 \%$ of salbutamol sulphate was released after an hour, whereas drug from the lactose-based spraydried powder formulation was released within $5 \mathrm{~min}$. Our results clearly demonstrate that the inclusion of $\mathrm{NaCMC}$ in spray-dried powder formulations increases the aerosolisation efficiency of the powder and also offers the potential for sustained drug release, which may be of benefit in the treatment of local and systemic conditions.
\end{abstract}

Key Words: Saccharides, Pulmonary Delivery, Sustained Release, Aerosolisation 


\section{Introduction}

Pulmonary drug delivery systems have been employed for the treatment of lung conditions such as asthma, chronic pulmonary infections and cystic fibrosis $[1,2]$, as inhalation offers direct access to the drug target, rapid onset of treatment, and lower doses (hence lower incidence of adverse drug effects) compared to other routes of administration [3]. In addition, the lungs have been considered as a potential non-invasive route for the administration of therapeutic biomacromolecules such as insulin, calcitonin, human growth hormone and non-viral gene vectors for the treatment of systemic conditions [1, 4-6], as this route avoids the first-pass metabolism and high enzymatic activity associated with oral drug administration [7].

Devices used to aerosolise drug particles for inhalation are typically based on one of three platforms: nebulizer, pressurised metered-dose inhaler (pMDI) or dry powder inhaler (DPI). The nebulizer atomises an aqueous solution or suspension by air jet or ultrasonication, and is especially suitable for infants, elderly or seriously ill patients. However, nebulizers are not portable and are associated with unstable and low drug delivery efficiency. Although the pMDI has been the most widely used device for pulmonary drug delivery, the drawbacks of this device include the need for patient coordination between inhalation and actuation and the contribution of propellants employed in the formulation of these devices to the 'greenhouse effect'. In contrast, DPIs, being breath-activated, propellant-free devices, have attracted substantial interest for the development of pulmonary drug delivery systems for local and systemic therapies.

For efficient deposition within the central and alveolar regions of the lung, the optimal aerodynamic diameter of particles for inhalation is approximately 1-5 $\mu \mathrm{m}$ [8]. Spray-drying 
is a common approach for powder preparation for a wide range of drug powders, and is especially suitable for preparing powders for inhalation because this process allows control over the particle size and shape, generating powders with narrow particle size distributions and low particle surface energy [9]. Furthermore, spray-drying enables the incorporation of excipients to improve the dispersibility of the powder, to improve the stability of the drug or the formulation on storage, to enhance the absorption of the drug across the pulmonary epithelium following delivery, or to generate powders that display a modified drug release profile [10].

Generally, drugs deposited on the pulmonary epithelium are quickly absorbed, which may give rise to toxicity and the need for repeated dosing for drugs with a short duration of action, particularly in the treatment of chronic diseases (for example salbutamol in the treatment of asthma). However, excessive dosing frequency is a well-documented cause of noncompliance in patients [11]. These problems may be potentially avoided by developing sustained release formulations which release drug steadily to maintain drug concentration and reduce peak plasma fluctuations, leading to a reduction in dosing frequency and improved patient compliance, and associated cost savings, thereby providing effective medical treatments for both local and systemic therapies [12]. Many interdependent factors, including the physicochemical characteristics of the drug, the preparation conditions, the ionic strength of the dissolution medium and the type of dissolution apparatus employed have been shown to influence the overall release of drug from a sustained release formulation in vitro.

Sustained release in the lung may be achieved by selecting excipients to retard the dissolution of the drug or by co-precipitating relatively insoluble materials with aqueous soluble drugs, although the organic excipients acceptable for inhalation into the human body are somewhat restricted. 
Lactose is traditionally used as excipient in dry powder formulations for inhalation, but spray-dried lactose powders are generally highly hygroscopic and particles are typically extremely cohesive, therefore that powders demonstrate poor aerosolisation performance and low delivery efficiency to the lungs [13]. Beta-cyclodextrin, an oligosaccharide, has been reported to enhance drug solubility, and acts as permeation enhancer by transporting the drug through the lipophilic surface of biological membranes [14]. Beta-cyclodextrin has been used to prepare spray-dried powders for pulmonary drug delivery which exhibit enhanced dispersibility and improved drug permeation [15]. Hooton and co-workers, investigating the use of a cohesive-adhesive force balance technique to compare the forces of attraction between salbutamol sulphate and a range of potential carrier particles, noted that betacyclodextrin-based powders demonstrated superior in vitro aerosolisation performance to lactose-based powders [16]. Sodium carboxymethylcellulose (NaCMC) and starch have been widely used in the pharmaceutical formulations for the improvement of mucoadhesion [17, 18] and for the sustained release of drugs [19]. The addition of NaCMC when preparing spray-dried enzyme powders maintains the bioactivity of enzymes during the spray-drying process, and is further able to improve the aerosolisation of the powder [20].

In this paper, lactose (disaccharide), beta-cyclodextrin (oligosaccharide), starch and NaCMC (polysaccharides) were employed as excipients in the preparation of spray-dried powders for the pulmonary drug delivery, with the aim of investigating the influence of the physiochemical properties of saccharides on the aerosolisation performance of, and the rate of drug release from, the resultant spray-dried powders, using salbutamol sulphate as a model drug. 


\section{Materials and Methods}

\subsection{Materials}

Lactose was purchased from Fisher (Loughborough, UK). Acetic acid, beta-cyclodextrin, soluble starch, sodium carboxymethylcellulose (NaCMC, 300-800 mPa s) were obtained from Aladdin Chemistry Co. Ltd (Shanghai, China). Salbutamol sulphate was purchased from Sigma-Aldrich (UK). HPLC-grade methanol was acquired from Spectrum Chemicals \& Laboratory Products (California, USA) and sodium dihydrogen phosphate was obtained from Sinopharm Chemical Reagent Co. Ltd (Shanghai, China). All other reagents used in this study were certified analytical reagent grade (Shanghai Chemical Reagent Company, Shanghai, China).

\subsection{Preparation of spray-dried powders}

The procedure for the preparation of spray-dried powders was following the approach as previously described [21]. In brief, lactose, beta-cyclodextrin, starch or NaCMC (3 g) were dissolved/dispersed in $200 \mathrm{~mL}$ of deionised distilled water to prepare the excipient formulation $(1.5 \% \mathrm{w} / \mathrm{v})$, into which salbutamol sulphate $(6 \mathrm{mg})$ was subsequently dissolved to prepare the spray-drying feedstocks. These feedstocks were then spray-dried (Büchi B-290 mini spray dryer, Büchi Labortechnik AG, Switzerland), operated at the following standard operating conditions: inlet temperature, $150^{\circ} \mathrm{C}$; pump setting, $450 \mathrm{~mL} / \mathrm{h}$; spray flow rate, 600 $\mathrm{L} / \mathrm{h}$; aspirator setting, $100 \%\left(40 \mathrm{~m}^{3} / \mathrm{h}\right)$. The outlet temperature was approximately $85^{\circ} \mathrm{C}$. The spray-dried powders were collected from the lower part of the cyclone and the collection vessel, and stored in a desiccator under partial vacuum. For each formulation, the spray drying process was carried out in triplicate.

\subsection{Characterisation of spray-dried powders}


The drug content of each powder was determined by HPLC, and expressed as the percentage of the anticipated amount. Each powder was measured in triplicate. The moisture content of the spray-dried powders was determined using thermogravimetric analysis (Q500, TA Instruments, New Castle, DE, USA). The samples (10 mg) were placed into platinum pans and analysed under a nitrogen purge $\left(20 \mathrm{~mL} \mathrm{~min}^{-1}\right)$ over the temperature range $40-140{ }^{\circ} \mathrm{C}$ at a heating rate of $10^{\circ} \mathrm{C}$ per minute. Measurements were performed in triplicate.

The morphology of the spray-dried particles was investigated using a scanning electron microscope (SEM, S-4700, Hitachi Co., Tokyo, Japan) operated at $15 \mathrm{kV}$ under high vacuum. Samples were sputter-coated with a thin layer of gold under partial vacuum (HITACHI E1010, Tokyo, Japan), and representative micrographs of spray-dried particles were captured.

Laser diffraction (Mastersizer 2000, Malvern Instruments, Malvern, UK) was used to determine the particle size of the spray-dried powders using a dry dispersion technique in air. The air pressure used was 4 bar, and was the same for each powder sample. For each sample, approximately $200 \mathrm{mg}$ of powder was used to achieve the required obscuration of $0.5-5 \%$, and the size and size distribution were subsequently determined. The measurements for each sample were performed in triplicate.

\subsection{HPLC analysis of salbutamol sulphate}

High performance liquid chromatography (HPLC) was employed to analyse salbutamol sulphate, using an Agilent 1260 infinity HPLC system, pump (1260, G1312B), autosampler (1260 ALS, G1329B), UV detector (1260 VWD, G1314F) and a 25 x $4.6 \mathrm{~cm}$ column filled with $5 \mu \mathrm{m}$ C-18 (ZORBAX Eclipse XDB-C18, Agilent, USA), with detection at $276 \mathrm{~nm}$. For the analysis, $\mathrm{NaH}_{2} \mathrm{PO}_{4}$ buffer $(80 \mathrm{mmol} / \mathrm{L})$ was prepared, filtered using a $0.2 \mu \mathrm{m}$ membrane, 
and adjusted to $\mathrm{pH} 3.1$ with phosphoric acid. The mobile phase comprised a solution of methanol: $\mathrm{NaH}_{2} \mathrm{PO}_{4}$ buffer $(20: 80 \mathrm{v} / \mathrm{v})$ at a flow rate of $1 \mathrm{~mL} / \mathrm{min}$. The retention time for salbutamol sulphate under these conditions was $5.3 \mathrm{~min}$.

\subsection{In-vitro powder aerosolisation}

The aerosolisation performance of the spray-dried powders from a dry powder inhaler (DPI) device was determined using a Next Generation Impactor (NGI, Copley Scientific, Nottingham, UK) equipped with a USP throat and pre-separator. The NGI is an eight-stage inertial impactor that separates an aerosol cloud into discrete size ranges based on aerodynamic diameter. For the test, powders $(25 \mathrm{mg})$ were accurately weighed and loaded into size 3 gelatin capsules, and subsequently placed into a Cyclohaler ${ }^{\circledR}$ (Pharmachemie BV, Netherlands) DPI device, connected via a mouthpiece adapter to the USP throat. The powders were subsequently aerosolized ( $35 \%$ relative humidity, $20^{\circ} \mathrm{C}$ ) at $60 \mathrm{~L} / \mathrm{min}$ for 5 seconds $[22,23]$. Two capsules (equivalent to $100 \mu \mathrm{g}$ salbutamol sulphate) were used for each test, and each powder was tested in triplicate. After aerosolisation, the capsules and inhaler device, the NGI throat, pre-separator, and stage 1 to the micro-orifice collector (MOC) were rinsed with $10 \mathrm{~mL}$ of deionized distilled water respectively for the determination of deposited drug. The sample was vortex-mixed for 30 minutes and then shaken overnight to ensure complete dissolution of any deposited drug. These solutions were subsequently filtered through a $0.45 \mu \mathrm{m}$ membrane, and $50 \mu \mathrm{L}$ of the sample was subjected to HPLC analysis. For each test, the total dose (TD) was defined as the mass of salbutamol sulphate loaded into the two capsules (theoretically $100 \mu \mathrm{g}$ ). The emitted dose (ED) was defined as the mass of powder loaded into the capsule that was released during aerosolisation, determined gravimetrically and expressed as a percentage of TD. The recovered dose (RD) was defined as the total mass of salbutamol sulphate detected after each test (i.e. capsule, 
inhaler, throat, pre-separator and stages 1-MOC), expressed as a percentage of TD. The fine particle dose (FPD) was defined as the mass of salbutamol sulphate detected on stages 2 to MOC of the NGI (effective cut-off diameter $4.46 \mu \mathrm{m}$ ). The fine particle fraction (FPF) was calculated as the ratio of FPD to RD, expressed as a percentage.

\subsection{Release of salbutamol sulphate from spray-dried powders}

The release of salbutamol sulphate from the spray-dried formulations was determined using a method based on the USP dissolution test $[24,25]$ using an RC806 dissolution apparatus (Tianjin University Precision Corporation, Tianjin, China). For each test, the spray-dried powders (containing $100 \mu \mathrm{g}$ of salbutamol sulphate) were added into $500 \mathrm{~mL}$ of phosphate buffered saline at $37^{\circ} \mathrm{C}$ with stirring at $50 \mathrm{rpm}$. At scheduled time intervals, aliquots of solution $(2 \mathrm{~mL})$ were withdrawn from the vessel and filtered through a $0.45 \mu \mathrm{m}$ membrane and subjected to HPLC analysis. A corresponding volume of fresh medium at $37^{\circ} \mathrm{C}$ was subsequently added into the vessel after each extraction.

\subsection{Statistical analysis}

The levels of significance are indicated in the legend of the respective graphs. Data are presented as mean \pm standard deviation $(S D ; n=3)$. Statistical analysis was performed using one-way ANOVA, Duncan's test $(p<0.05)$. 


\section{Results and Discussion}

\subsection{Spray-dried powder characteristics}

The drug content for the lactose-, beta-cyclodextrin-, starch- and NaCMC-based spray-dried powders was $99.7 \pm 2.4 \%, 100.2 \pm 1.5 \%, 98.7 \pm 3.5 \%$ and $101.4 \pm 2.8 \%$ of the anticipated amount, demonstrating that there was no deleterious effect of the spray-drying process on salbutamol sulphate.

The yield and moisture content of the spray-dried powders are presented in Fig. 1. The spraydried lactose-based powder exhibited a relatively poor yield of $46 \%$, with much of the powder deposited in the top of the cyclone, and therefore unrecoverable. The other powders demonstrated lower adhesion to the cyclone surface, being predominantly deposited in the collection vessel, resulting in statistically higher $(p<0.05)$ yields of $73 \%, 74 \%, 56 \%$ for the beta-cyclodextrin-, starch- and NaCMC-based powders, respectively.

The moisture content of spray-dried powders was in the range from $3.2 \%$ to $9.7 \% \mathrm{w} / \mathrm{w}$ (Fig.

1). Previous studies have demonstrated that increasing the aspirator capacity or inlet temperature is associated with a decrease in moisture content, whereas increasing the feed flow or reducing the outlet air temperature results in a lower drying capacity and hence a higher moisture content in the powder product. In our study, all powders were spray-dried using the same conditions; however, the moisture content of the NaCMC-based powder was substantially higher than that of the other powders. This is in agreement with other studies on NaCMC-based spray-dried powders, which demonstrated that increasing the proportion of $\mathrm{NaCMC}$ in a spray-dried powder is associated with an increase in moisture content [20, 26]. NaCMC disperses to form a colloidal solution when added to water [27], and it is feasible 
water becomes entrapped in this matrix during the spray-drying process, resulting in a higher moisture content. The moisture contents of the other spray-dried powders are in line with other studies, which report typical moisture contents in the region of 3-7.5\% w/w [28-32].

The size, shape and surface morphology of the spray-dried powders are illustrated in Fig. 2. All powders appeared to comprise spherical or near-spherical particles of a suitable physical diameter for inhalation, with a particle diameter less than $10 \mu \mathrm{m}$ and in some powders a subpopulation of smaller particles of approximately $2 \mu \mathrm{m}$. While spray-dried lactose-based particles appeared to be perfect spheres with smooth surfaces (Fig. 2A), the particles in the spray-dried beta-cyclodextrin-, starch- and NaCMC-based powders exhibited dimpled surface morphologies (Figures 2B-D). Such wrinkled morphology is commonly observed in spraydried powders designed for inhalation, and has been associated with an improvement in aerosolisation performance $[33,34]$.

In order to further investigate the physical diameter of the spray-dried powder particles, laser diffraction was employed to determine the particle size distribution (Fig. 3 and Table 1). The data are expressed in terms of the particle diameter at 10,50 and $90 \%$ of the volume distribution $(\mathrm{d}[\mathrm{v}, 10], \mathrm{d}[\mathrm{v}, 50]$ and $\mathrm{d}[\mathrm{v}, 90]$, respectively). The span of the volume distribution, a measure of the width of the volume distribution relative to the median diameter $(d[v, 50])$, was calculated from $(\mathrm{d}[\mathrm{v}, 90]-\mathrm{d}[\mathrm{v}, 10]) / \mathrm{d}[\mathrm{v}, 50])$. In addition, the mean diameter over the volume distribution $(\mathrm{D}[4,3])$ is reported. The lactose-based spray-dried powder showed a bimodal size distribution, with a large population of dry powders over $100 \mu \mathrm{m}$, resulting in a mean diameter of $28.3 \mu \mathrm{m}$ and a span of 59.4. The SEM image of this powder (Fig. 2A) clearly showed particles less than $10 \mu \mathrm{m}$ in diameter, therefore the laser diffraction data suggest cohesion between individual particles, resulting in large agglomerates that fail to 
break up during the dry dispersion measurement. This suggests that the lactose-based powder has poor dispersibility in an airflow and therefore may perform poorly during aerosolisation. The spray-dried NaCMC-based powder exhibited a broad particle size distribution, with a mean diameter of $9.6 \mu \mathrm{m}$ and span of 3.7. This is also indicative of a degree of cohesion between particles, although to a lesser extent than was observed with the lactose-based powder. In contrast, the starch- and beta-cyclodextrin-based powders demonstrated unimodal particle size distributions (mean diameter $2.9 \mu \mathrm{m}$ and $2.6 \mu \mathrm{m}$, respectively), suggesting no obvious aggregation between particles in these powders. These data suggest that the betacyclodextrin- and starch- and, to a lesser extent, NaCMC-based spray-dried powders are potentially more suitable for pulmonary delivery than the lactose-based spray-dried powder, with a greater proportion of particles/aggregates less than $3 \mu \mathrm{m}$ for deposition in the respiratory tract [35].

\subsection{In-vitro aerosol deposition}

The Next Generation Impactor (NGI) was used to assess the aerodynamic performance of the spray-dried powders following aerosolisation using a Cyclohaler® dry powder inhaler device. The lactose-based spray-dried powder demonstrated a poor emitted dose (64.9\%), whereas the beta-cyclodextrin-, starch- and NaCMC-based spray-dried powders demonstrated higher emitted doses $(85.3 \%, 93.6 \%$ and $98.6 \%$, respectively; $p<0.05$, Table 2$)$. Although for these three spray-dried powders, a greater proportion of the loaded powder was released from the capsule during aerosolisation in comparison to the lactose-based powder, more important is to determine the site of deposition of the drug once aerosolised. The NGI is a widely recognised in vitro characterisation tool used to determine the respirable fraction of an emitted dose based on aerodynamic particle size. Following aerosolisation of the powder into the NGI, the mass of salbutamol sulphate deposited within the Cyclohaler@ DPI device, the 
USP throat, the pre-separator and stages 1-MOC of the NGI was determined using HPLC, as described in Section 2.5. The deposition pattern of the four spray-dried powders is illustrated in Fig. 4. A high proportion of the salbutamol contained in the lactose-based spray-dried powder was detected in the capsule and Cyclohaler® DPI device and the USP throat, with only minimal quantities detected in the lower stages of the NGI. The low FPD and FPF of this powder (Table 2) clearly demonstrate that the lactose-based spray-dried powder exhibited poor aerodynamic properties; these findings correlate well with the observation that this powder exhibited poor deagglomeration during particle sizing, resulting in a mean diameter of $28 \mu \mathrm{m}$ (Table 1). Inhalation of this powder is predicted to result in low delivery of salbutamol sulphate to the lungs, with substantial deposition on the back of the throat, potentially leading to local or systemic side effects. In contrast, the beta-cyclodextrin-, starch- and NaCMC-based spray-dried powders all demonstrated a significantly lower $(p<0.05)$ deposition of salbutamol sulphate in the USP throat and higher $(p<0.05)$ deposition on NGI stages 2, 3, 4 and 5. The FPD and FPF of these three powders were significantly higher $(p<0.05)$ than those of the lactose-based powder, with the lactose-based powder demonstrating an FPF of $11 \%$, whereas the other powders all exhibited FPFs greater than 40\%. A recent study by Mishra and Mishra investigated the use of NaCMC to generate spray-dried powders containing doxycycline hycolate. They found that, using an optimised formulation incorporating doxycycline hycolate, $\mathrm{NaCMC}$ and leucine as a dispersibility enhancer, an FPF of $49 \%$ could be obtained using an Andersen Cascade Impactor, although the authors fail to disclose the dose of drug delivered during the aerosolisation test, or indeed the final composition of the microparticles, such as drug load [36]. However, the study suggests that further improvement in the aerodynamic properties of our powders could be obtained through the inclusion of leucine in the spray-drying feedstock, as has been observed in other studies $[30,37,38]$. 


\subsection{In-vitro sustained release}

As expected, the lactose-based spray dried powders showed an initial burst release of salbutamol sulphate, with approximately $75 \%$ of drug released within $1 \mathrm{~min}$, and complete release within 5 min (Fig. 5). Rapid drug dissolution was also observed from the starchbased powder, with $70 \%$ of salbutamol sulphate released in the initial burst, and nearly $90 \%$ released within 10 min. Drug release from the beta-cyclodextrin-based powder was slightly slower, with full drug release observed after 15 min dissolution. In comparison, the NaCMCbased powder exhibited a sustained drug release profile, with no obvious initial burst as was seen with the other powders. Approximately $20 \%$ of the drug load was released in the first minute, with 180 min dissolution time required to achieve $85 \%$ drug release. Conti and coworkers, investigating the release of drug from matrix tablets, observed that at $\mathrm{pH} 6.8$, diltiazem was released more rapidly from NaCMC matrices than from hydroxypropylmethylcellulose (HPMC) matrices. They attributed this to the high solubility of $\mathrm{NaCMC}$ at this $\mathrm{pH}$, leading to rapid erosion of the gel layer surrounding the matrix and a high degree of erosion of the matrix overall; release from HPMC matrices, on the other hand, was related to diffusion of the drug through the gel layer, rather than erosion [39] . In contrast, Farid and co-workers recently examined release of salbutamol sulphate from nasal inserts prepared from a number of gel-forming polymers, including NaCMC. They found that NaCMC inserts exhibited a high water uptake, leading to swelling of the insert and creation of a thick gel layer on the swollen insert surface. In addition, they suggested that at the $\mathrm{pH}$ of the simulated nasal fluid used ( $\mathrm{pH} 6.5$ ), salbutamol sulphate ( $\mathrm{pKa} 9.5$ ) would be ionised, which may result in binding of the cationic drug to the anionic polymer through electrostatic attraction. They commented that this would result in a reduced rate of diffusion of salbutamol sulphate through the gel layer, leading to reduced and retarded drug release. 
Analysis of the kinetics of drug release suggested zero-order release controlled by matrix relaxation and diffusion of drug through the gel layer formed as the insert swelled [40]. Likewise, Mishra and Mishra found that rate of release of drug (doxycycline hyclate) from $\mathrm{NaCMC}$-based spray-dried microspheres was slower than from NaCMC-free microspheres, and related this to the creation of a gel barrier formed when the hydrophilic polymer swelled on coming into contact with water [36]. Our data appear to support these studies, with NaCMC-based powders hydrating to create a gel layer from which drug is gradually released, whereas drug release is more rapid from lactose-, starch- and beta-cyclodextrin-based powders, as no gel layer is created following immersion of these powders in water. 


\section{Conclusion}

In this study, we have demonstrated that spray-drying a feedstock containing NaCMC generates powders that exhibit sustained drug release and good aerosolisation properties. Unlike the formulation of conventional DPI systems, where crystalline drug is blended with a larger carrier particle (typically lactose) to improve powder flow and aerodynamic properties, our powder can be formulated as a DPI without the need for the addition of further excipients. NaCMC, a water-dispersible polysaccharide, is widely used in a range of formulations for oral, topical and parenteral routes of administration, and is regarded as a non-toxic and non-irritant material [27]. Studies have shown that NaCMC reduces the rate of mucocilliary clearance and enhance uptake across respiratory epithelia, without causing an increase in mortality $[41,42]$. Although further testing of the suitability of NaCMC for administration to the lung would be required, these studies suggest that NaCMC-based spraydried powders would be a promising approach to the development of highly respirable formulations that exhibit sustained release properties.

\section{Acknowledgements}

The authors would like to acknowledge the support of the Natural Science Foundation Committee of Jiangsu Province in China (BK2011295). 


\section{References}

[1] J.O.H. Sham, Y. Zhang, W.H. Finlay, W.H. Roa, R. Löbenberg, Formulation and characterization of spraydried powders containing nanoparticles for aerosol delivery to the lung, Int. J. Pharm. 269 (2004) 457-467.

[2] L. Ely, W. Roa, W.H. Finlay, R. Löbenberg, Effervescent dry powder for respiratory drug delivery, Eur. J. Pharm. Biopharm. 65 (2007) 346-353.

[3] S. Azarmi, W.H. Roa, R. Löbenberg, Targeted delivery of nanoparticles for the treatment of lung diseases, Adv. Drug Del. Rev. 60 (2008) 863-875.

[4] S. Kobayashi, S. Kondo, K. Juni, Pulmonary delivery of salmon calcitonin dry powders containing absorption enhancers in rats, Pharm. Res. 13 (1996) 80-83.

[5] M. Jalalipour, A.R. Najafabadi, K. Gilani, H. Esmaily, H. Tajerzadeh, Effect of dimethyl-beta-cyclodextrin concentrations on the pulmonary delivery of recombinant human growth hormone dry powder in rats, J. Pharm. Sci. 97 (2008) 5176-5185.

[6] H.-Y. Li, H. Neill, R. Innocent, P. Seville, I. Williamson, J.C. Birchall, Enhanced dispersibility and deposition of spray-dried powders for pulmonary gene therapy, J. Drug Target. 11 (2003) 425-432.

[7] J.S. Patton, Mechanisms of macromolecule absorption by the lungs, Adv. Drug Del. Rev. 19 (1996) 3-36.

[8] W. Glover, H.-K. Chan, S. Eberl, E. Daviskas, J. Verschuer, Effect of particle size of dry powder mannitol on the lung deposition in healthy volunteers, Int. J. Pharm. 349 (2008) 314-322.

[9] H.-K. Chan, Dry powder aerosol drug delivery: Opportunities for colloid and surface scientists, Colloids Surf. Physicochem. Eng. Aspects 284-285 (2006) 50-55.

[10] P.C. Seville, H.-y. Li, T.P. Learoyd, Spray-dried powders for pulmonary drug delivery, Crit. Rev. Ther. Drug Carrier Syst. 24 (2007) 307-360.

[11] E. Derom, L. Thorsson, Factors affecting the clinical outcome of aerosol therapy, in: H. Bisgaard, C. O'Callaghan, G.C. Smaldone (Eds.) Drug Delivery to the Lung, Marcel Dekker, New York, NY, USA, 2002, pp. 143-171.

[12] X.M. Zeng, G.P. Martin, C. Marriott, The controlled delivery of drugs to the lung, Int. J. Pharm. 124 (1995) 149-164.

[13] D.O. Corrigan, O.I. Corrigan, A.M. Healy, Predicting the physical state of spray dried composites: salbutamol sulphate/lactose and salbutamol sulphate/polyethylene glycol co-spray dried systems, Int. J. Pharm. 273 (2004) 171-182.

[14] B. Prakash Rao, Suresh, S., Narendra, C., Recent advances in cyclodextrin complexes: mechanistic analysis as permeation enhancer, Indian J. Pharm. Educ. Res. 41 (2007) 102-113.

[15] H.Y. Li, P.C. Seville, I.J. Williamson, J.C. Birchall, The use of absorption enhancers to enhance the dispersibility of spray-dried powders for pulmonary gene therapy, J. Gene Med. 7 (2005) 1035-1043.

[16] J.C. Hooton, M.D. Jones, R. Price, Predicting the behavior of novel sugar carriers for dry powder inhaler formulations via the use of a cohesive-adhesive force balance approach, J. Pharm. Sci. 95 (2006) 1288-1297.

[17] A. Momeni, M.H. Mohammadi, Respiratory delivery of theophylline by size-targeted starch microspheres for treatment of asthma, J. Microencapsul. 26 (2009) 701-710.

[18] D. Coucke, M. Schotsaert, C. Libert, E. Pringels, C. Vervaet, P. Foreman, X. Saelens, J.P. Remon, Spraydried powders of starch and crosslinked poly(acrylic acid) as carriers for nasal delivery of inactivated influenza vaccine, Vaccine 27 (2009) 1279-1286.

[19] G.J. Vergote, C. Vervaet, I. Van Driessche, S. Hoste, S. De Smedt, J. Demeester, R.A. Jain, S. Ruddy, J.P. Remon, An oral controlled release matrix pellet formulation containing nanocrystalline ketoprofen, Int. J. Pharm. 219 (2001) 81-87.

[20] H.-Y. Li, X. Song, P.C. Seville, The use of sodium carboxymethylcellulose in the preparation of spray-dried proteins for pulmonary drug delivery, Eur. J. Pharm. Sci. 40 (2010) 56-61.

[21] H.-Y. Li, J. Birchall, Chitosan-modified dry powder formulations for pulmonary gene delivery, Pharm. Res. 23 (2006) 941-950.

[22] P. Begat, Price, R., Harris, H., Morton, D.A.V., Staniforth, J.N., The influence of force control agents on the cohesive-adhesive balance in dry powder inhaler formulations, KONA 23 (2005) 109-121.

[23] A. Kamiya, M. Sakagami, P.R. Byron, Cascade impactor practice for a high dose dry powder inhaler at 90 L/min: NGI versus modified 6-stage and 8-stage ACI, J. Pharm. Sci. 98 (2009) 1028-1039.

[24] USP, United States Pharmacopeia, 26 ed., United States Pharmacopia Convention INC, Rockville, MD, 2000.

[25] V. Gray, G. Kelly, M. Xia, C. Butler, S. Thomas, S. Mayock, The science of USP 1 and 2 dissolution: present challenges and future relevance, Pharm. Res. 26 (2009) 1289-1302.

[26] H.-Y. Li, P.C. Seville, Novel pMDI formulations for pulmonary delivery of proteins, Int. J. Pharm. 385 (2010) 73-78. 
[27] D. Parsons, Carboxymethylcellulose sodium, in: A.H. Kibbe (Ed.) Handbook of Pharmaceutical Excipients, Pharmaceutical Press, London, 2000, pp. 87-90.

[28] K. Ståhl, M. Claesson, P. Lilliehorn, H. Lindén, K. Bäckström, The effect of process variables on the degradation and physical properties of spray dried insulin intended for inhalation, Int. J. Pharm. 233 (2002) 227 237.

[29] N.Y.K. Chew, P. Tang, H.-K. Chan, J.A. Raper, How much particle surface corrugation is sufficient to improve aerosol performance of powders?, Pharm. Res. 22 (2005) 148-152.

[30] P.C. Seville, T.P. Learoyd, H.Y. Li, I.J. Williamson, J.C. Birchall, Amino acid-modified spray-dried powders with enhanced aerosolisation properties for pulmonary drug delivery, Powder Technol. 178 (2007) 4050 .

[31] T.P. Learoyd, J.L. Burrows, E. French, P.C. Seville, Chitosan-based spray-dried respirable powders for sustained delivery of terbutaline sulfate, Eur. J. Pharm. Biopharm. 68 (2008) 224-234.

[32] T.P. Learoyd, J.L. Burrows, E. French, P.C. Seville, Modified release of beclometasone dipropionate from chitosan-based spray-dried respirable powders, Powder Technol. 187 (2008) 231-238.

[33] N.Y. Chew, H.K. Chan, Use of solid corrugated particles to enhance powder aerosol performance, Pharm. Res. 18 (2001) 1570-1577.

[34] H. Adi, D. Traini, H.-K. Chan, P.M. Young, The influence of drug morphology on aerosolisation efficiency of dry powder inhaler formulations, J. Pharm. Sci. 97 (2008) 2780-2788.

[35] D.A. Edwards, A. Ben-Jebria, R. Langer, Recent advances in pulmonary drug delivery using large, porous inhaled particles, J. Appl. Physiol. 85 (1998) 379-385.

[36] M. Mishra, B. Mishra, Formulation optimization and characterization of spray dried microparticles for inhalation delivery of doxycycline hyclate, Yakugaku Zasshi. 131 (2011) 1813-1825.

[37] T. Sou, L.M. Kaminskas, T.H. Nguyen, R. Carlberg, M.P. McIntosh, D.A.V. Morton, The effect of amino acid excipients on morphology and solid-state properties of multi-component spray-dried formulations for pulmonary delivery of biomacromolecules, Eur. J. Pharm. Biopharm. 83 (2013) 234-243.

[38] T. Sou, M.P. McIntosh, L.M. Kaminskas, R.J. Prankerd, D.A.V. Morton, Designing a Multicomponent Spray-Dried Formulation Platform for Pulmonary Delivery of Biomacromolecules: The Effect of Polymers on the Formation of an Amorphous Matrix for Glassy State Stabilization of Biomacromolecules, Drying Technol. 31 (2013) 1451-1458.

[39] S. Conti, L. Maggi, L. Segale, E. Ochoa Machiste, U. Conte, P. Grenier, G. Vergnault, Matrices containing NaCMC and HPMC: 1. Dissolution performance characterization, Int. J. Pharm. 333 (2007) 136-142.

[40] R.M. Farid, M.A. Etman, A.H. Nada, A.E.A.R. Ebian, Formulation and in vitro evaluation of salbutamol sulphate in situ gelling nasal inserts, AAPS PharmSciTech 14 (2013) 712-718.

[41] P.L. Sinn, A.J. Shah, M.D. Donovan, P.B. McCray, Viscoelastic gel formulations enhance airway epithelial gene transfer with viral vectors, Am. J. Respir. Cell Mol. Biol. 32 (2005) 404-410.

[42] U. Griesenbach, C. Meng, R. Farley, M.Y. Wasowicz, F.M. Munkonge, M. Chan, C. Stoneham, S.G. Sumner-Jones, I.A. Pringle, D.R. Gill, S.C. Hyde, B. Stevenson, E. Holder, H. Ban, M. Hasegawa, S.H. Cheng, R.K. Scheule, P.L. Sinn, P.B. McCray, Jr., E.W.F.W. Alton, The use of carboxymethylcellulose gel to increase non-viral gene transfer in mouse airways, Biomaterials 31 (2010) 2665-2672. 
Table 1. Particle size distribution (mean $\pm \mathrm{SD}, \mathrm{n}=3$ ) of lactose-, beta-cyclodextrin-, starch- and NaCMCbased spray-dried powders

\begin{tabular}{lccccc}
\hline Spray-dried powders & $\mathrm{d}[\mathrm{v}, 10] \quad(\mu \mathrm{m})$ & $\begin{array}{c}\mathrm{d}[\mathrm{v}, 50] \\
(\mu \mathrm{m})\end{array}$ & $\begin{array}{c}\mathrm{d}[\mathrm{v}, 90] \\
(\mu \mathrm{m})\end{array}$ & Span & $\begin{array}{c}\mathrm{D}[4,3] \\
(\mu \mathrm{m})\end{array}$ \\
\hline Lactose & $0.77(0.02)$ & $2.57(0.01)$ & $153.81(6.02)$ & $59.43(1.02)$ & $28.34(0.62)$ \\
Beta-cyclodextrin & $0.95(0.04)$ & $2.29(0.02)$ & $4.60(0.04)$ & $1.59(0.01)$ & $2.56(0.01)$ \\
Starch & $0.98(0.03)$ & $2.56(0.04)$ & $5.36(0.03)$ & $1.71(0.01)$ & $2.91(0.02)$ \\
NaCMC & $1.13(0.01)$ & $5.98(0.05)$ & $23.29(0.31)$ & $3.70(0.02)$ & $9.55(0.05)$ \\
\hline
\end{tabular}

$\mathrm{d}[\mathrm{v}, \chi]$ : Particle diameter at $\chi \%$ of the volume distribution.

Span: Width of the volume distribution, relative to the median diameter (found from $(\mathrm{d}[\mathrm{v}, 90]-$ $\mathrm{d}[\mathrm{v}, 10]) / \mathrm{d}[\mathrm{v}, 50])$.

$\mathrm{D}[4,3]$ : Volume weighted mean diameter. 
Table 2. Aerosolisation parameters of lactose-, beta-cyclodextrin-, starch- and NaCMC-based spray-dried powders (the data expressed as mean $\pm \mathrm{SD}, \mathrm{n}=3$ ).

\begin{tabular}{lccccc}
\hline Spray-dried powders & $\begin{array}{c}\text { Emitted } \\
\text { Dose }(\%)\end{array}$ & $\begin{array}{c}\text { Fine Particle } \\
\text { Dose } \\
\text { (FPD; } \mathrm{mcg})\end{array}$ & $\begin{array}{c}\text { Fine Particle } \\
\text { Fraction } \\
\text { (FPF; } \%)\end{array}$ & $\begin{array}{c}\text { Recovered } \\
\text { Dose } \\
(\mathrm{mcg})\end{array}$ & $\begin{array}{c}\text { Recovered Fraction } \\
\text { (\% of total dose) }\end{array}$ \\
\hline Lactose & $64.9(3.4)$ & $7.9(0.5)$ & $11.2(0.5)$ & $70.6(3.6)$ & $71.7(3.6)$ \\
Beta-cyclodextrin & $85.3(3.1)$ & $30.7(8.2)$ & $40.3(2.2)$ & $75.6(5.1)$ & $72.0(4.8)$ \\
Starch & $93.6(1.2)$ & $32.4(1.1)$ & $47.0(1.7)$ & $68.9(4.5)$ & $66.9(4.4)$ \\
NaCMC & $98.6(1.1)$ & $30.4(1.7)$ & $45.0(1.4)$ & $67.4(1.6)$ & $65.6(1.5)$ \\
\hline
\end{tabular}




\section{Figure captions}

Fig. 1. Physical properties of spray-drying powders. Data represented as mean \pm s.e.m., $n=3$. Statistical analysis by one-way analysis of variance $(p<0.05)$. * Significant difference from lactosebased spray-dried powder.

Fig. 2. Spray-dried powder morphology visualized by scanning electron microscopy. A) lactose-based powders; B) beta-cyclodextrin-based powders; C) starch-based powders; D) NaCMC-based powder $(\operatorname{Bar}=10 \mu \mathrm{m})$.

Fig. 3. Particle size distribution of spray-dried powders. The particle size distribution of lactose-, beta-cyclodextrin, starch- and NaCMC-based spray-dried powders was determined by laser diffraction.

Fig. 4. In-vitro aerosol deposition of lactose-, beta-cyclodextrin-, starch- and NaCMC-based spraydried powders. Approximately $50 \mathrm{mg}$ of dry powders (equivalent to $100 \mu \mathrm{g}$ of SS) was accurately weighed into two gelatin capsules (size 3), inserted into the dry powder inhaler that was connected to NGI. The dry powders were aerosolized $\left(35 \%\right.$ of relative humidity, $\left.20^{\circ} \mathrm{C}\right)$ at $60 \mathrm{~L} / \mathrm{min}$ flow rate for 5 seconds. The collected SS was analyzed using a validated HPLC method. Data represented as mean \pm s.e.m., $n=3$. Statistical analysis by one-way analysis of variance $(p<0.05)$. * Significant difference from lactose-based spray-dried powders.

Fig. 5. In-vitro sustained release of salbutamol sulphate from the formulation. The investigation of drug release from dry powder formulations was performed at $37^{\circ} \mathrm{C}$ with paddles operating at $50 \mathrm{rpm}$ in a dissolution bath. At scheduled time intervals, samples were obtained and subsequently analyzed via HPLC to determine the released drug. 
Fig. 1

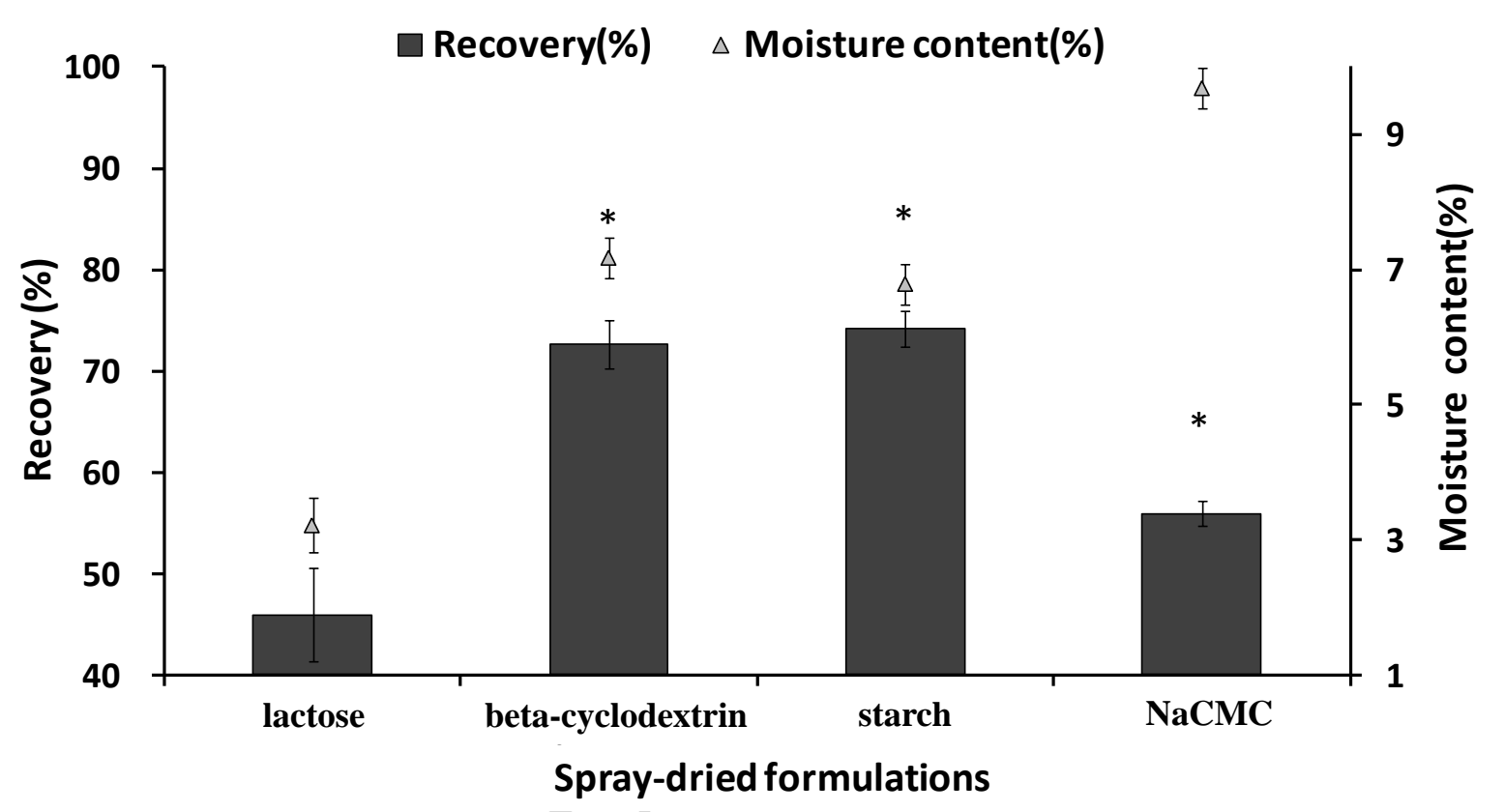




\section{ACCEPTED MANUSCRIPT}

Fig. 2
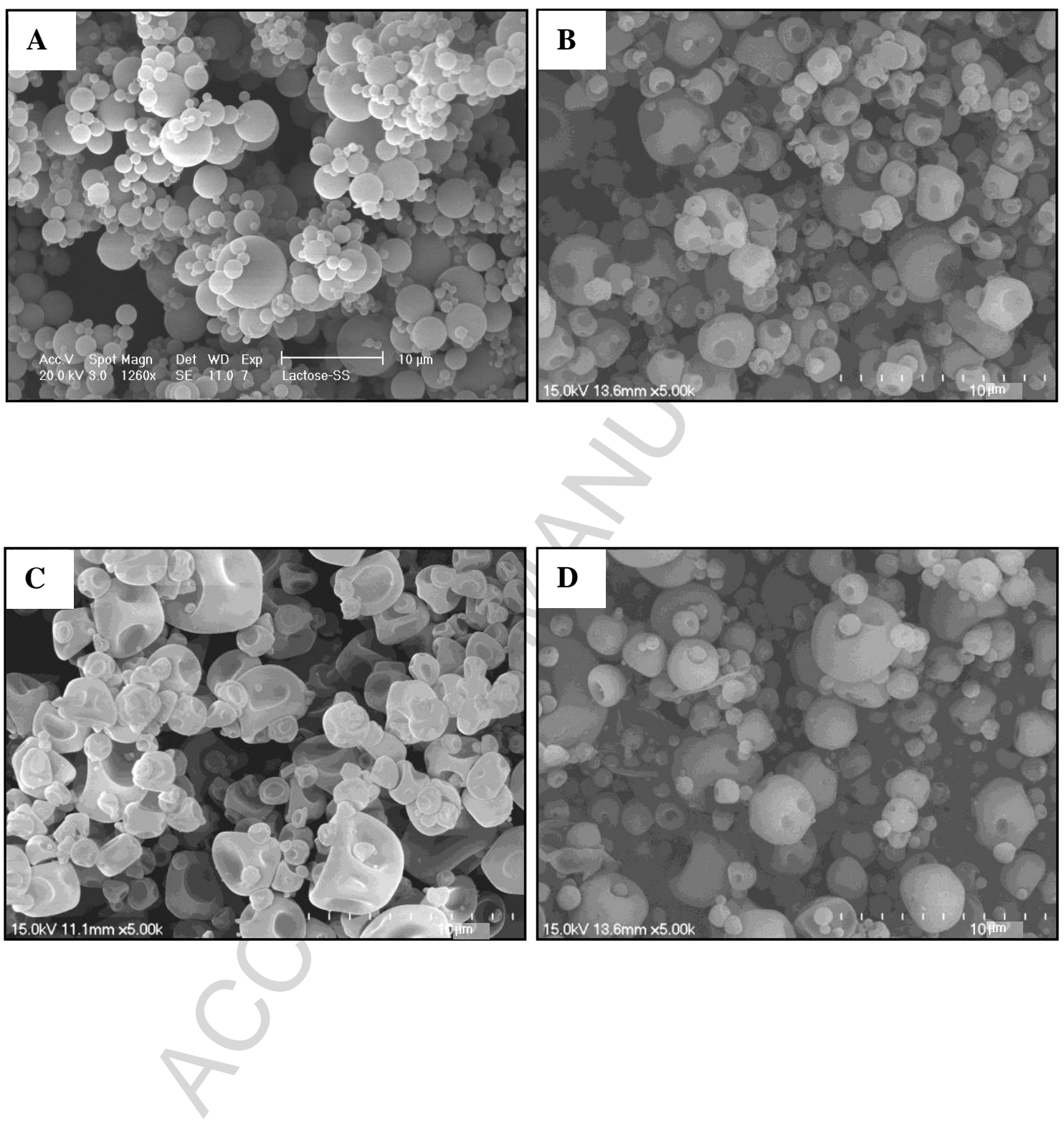
Fig. 3

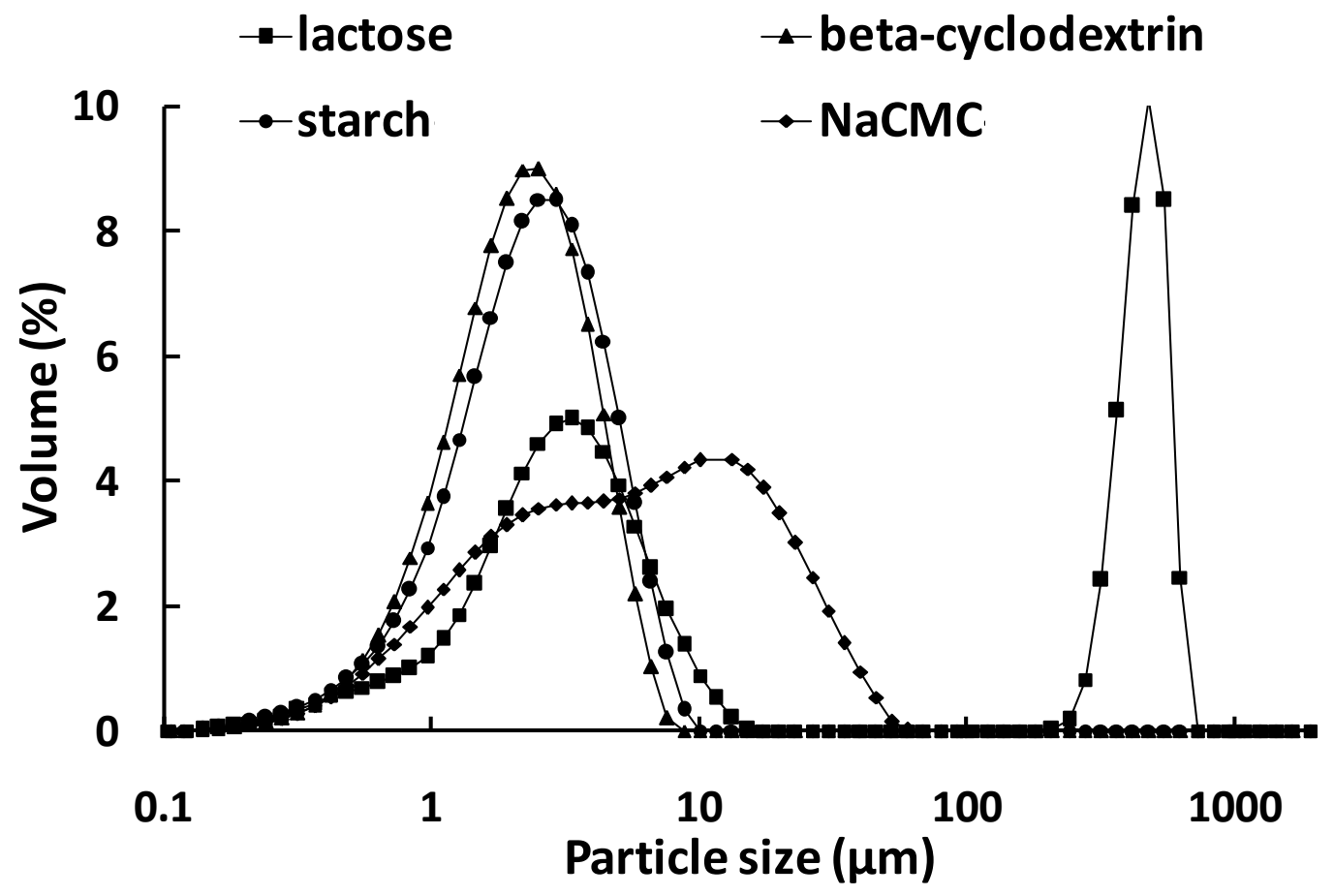


Fig. 4

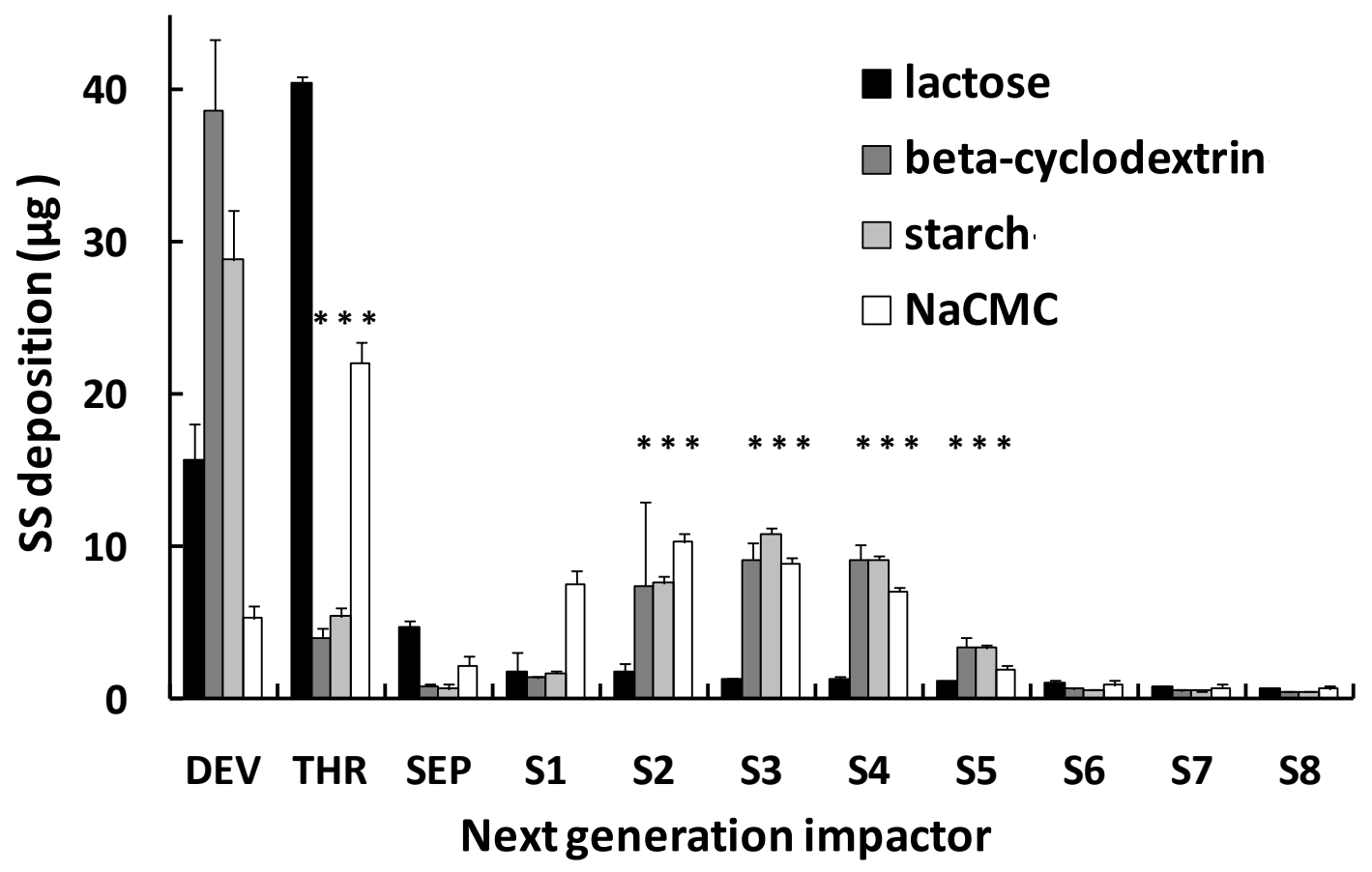


Fig. 5

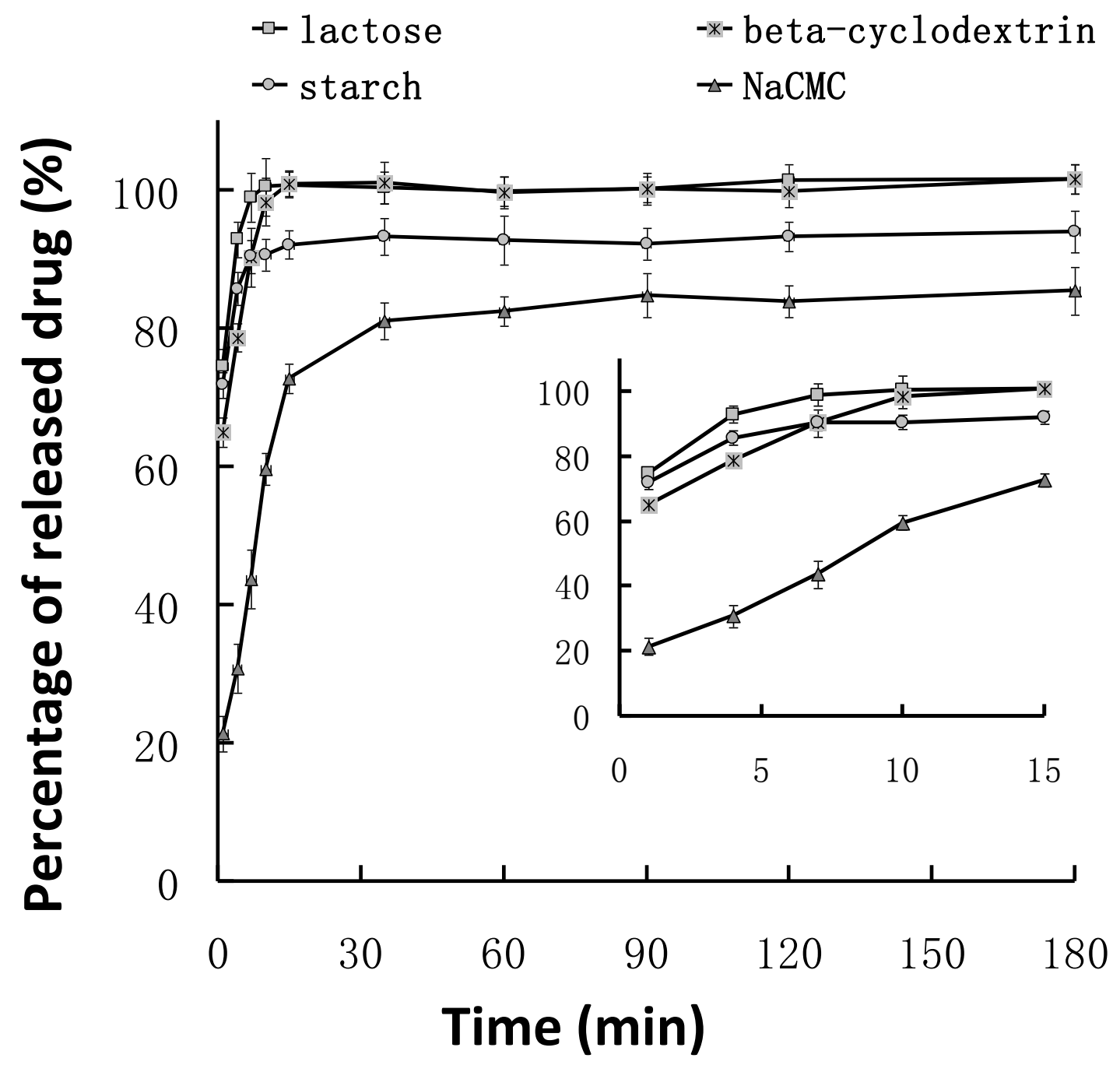




\section{Author Biographies}

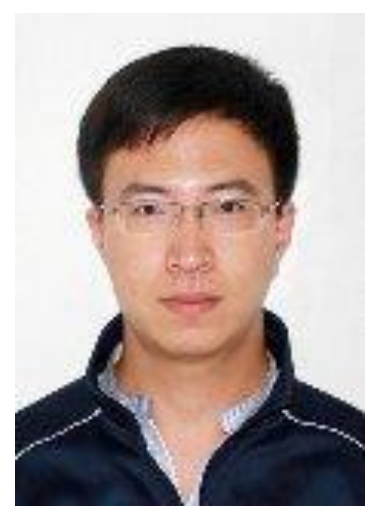

En-Yu Xu obtained his degrees of BSc (2009, Pharmacy) and MSc

(2013, Chemistry) from Liaoning Normal University. In 20112013, he undertook collaborative research with Soochow University, focusing on the development of dry powder inhaler formulations for pulmonary drug delivery. $\mathrm{Mr} \mathrm{Xu}$ is currently appointed as a lecturer in the College of Basic Medical Science, China Medical University.

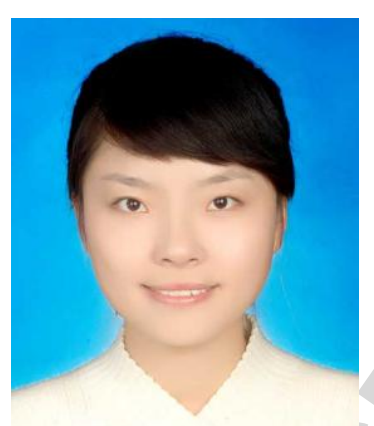

Jing Guo obtained her BSc (2008) from Nanjing University of Traditional Chinese Medicine, and MSc (2011) in pharmacy from China Pharmaceutical University. Mrs Guo then joined Soochow University as a Research Technician and worked in dry powder formulations for inhalation. Mrs Guo has excellent experimental skills, and expertise in the preparation and characterization of nano spray-dried formulations for pulmonary delivery of chemicals and biomolecules. Mrs Guo was awarded the 'people scholarship' in 2004 and 2005.

Ying Xu obtained her BSc (1995, Organic Chemistry) and MSc (2005, Inorganic Chemistry) from Soochow University. During 1995-2001, Mrs Xu worked at Soochow University and then at the 
Information Optical Engineering Institute of Soochow University. Mrs $\mathrm{Xu}$ moved to Testing and Analysis Centre of Soochow University in 2001, since when she had focused on the research into thermal properties of a variety of materials. Mrs Xu recently focused on research into thermal transitions of inhaled dosage forms with the aim of establishing correlations between polymorphs and aerosol performance.

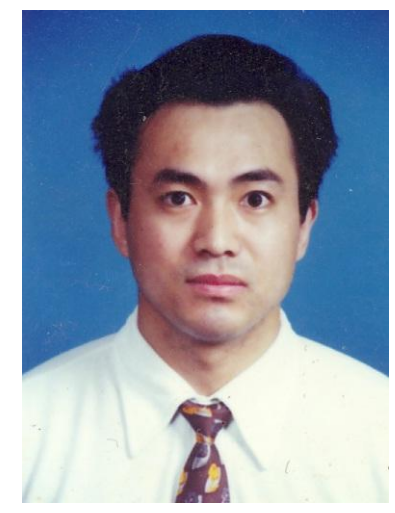

Hao-Ying Li obtained his degrees of BSc (1995, Chemistry) and MSc (1998, Biochemical Engineering) from Dalian University of Technology, and PhD (2001, Biomaterials) from the Chinese Academy of Sciences. He then worked as Postdoctoral Research Associates and Research Fellows in several UK universities (Cardiff University, University of London, Aston University and University College London. He was appointed to a professorial position at Soochow University in 2010. Dr Li has expertise in chemistry and pharmaceutical formulations especially inhaled dosage forms, and had a number of high quality publications in novel aerosols for pulmonary drug delivery.

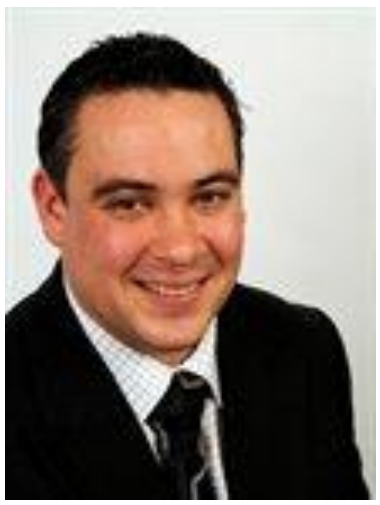

Peter Seville graduated from Cardiff University (BPharm, 1994; $\mathrm{PhD}, 2000$ ), after which he undertook postdoctoral research in the area of gene therapy for pulmonary delivery. Dr Seville was subsequently appointed as a lecturer, then senior lecturer, in pharmaceutics at Aston University, and is currently a senior lecturer in pharmaceutics at University of Birmingham. Dr Seville has a 
long history of research in the development of inhalable formulations, and in particular expertise in the use of spray-drying technology to generate powders with enhanced aerosolisation properties, an area in which he and $\mathrm{Dr}$ Li have a number of joint publications. 
Graphical abstract

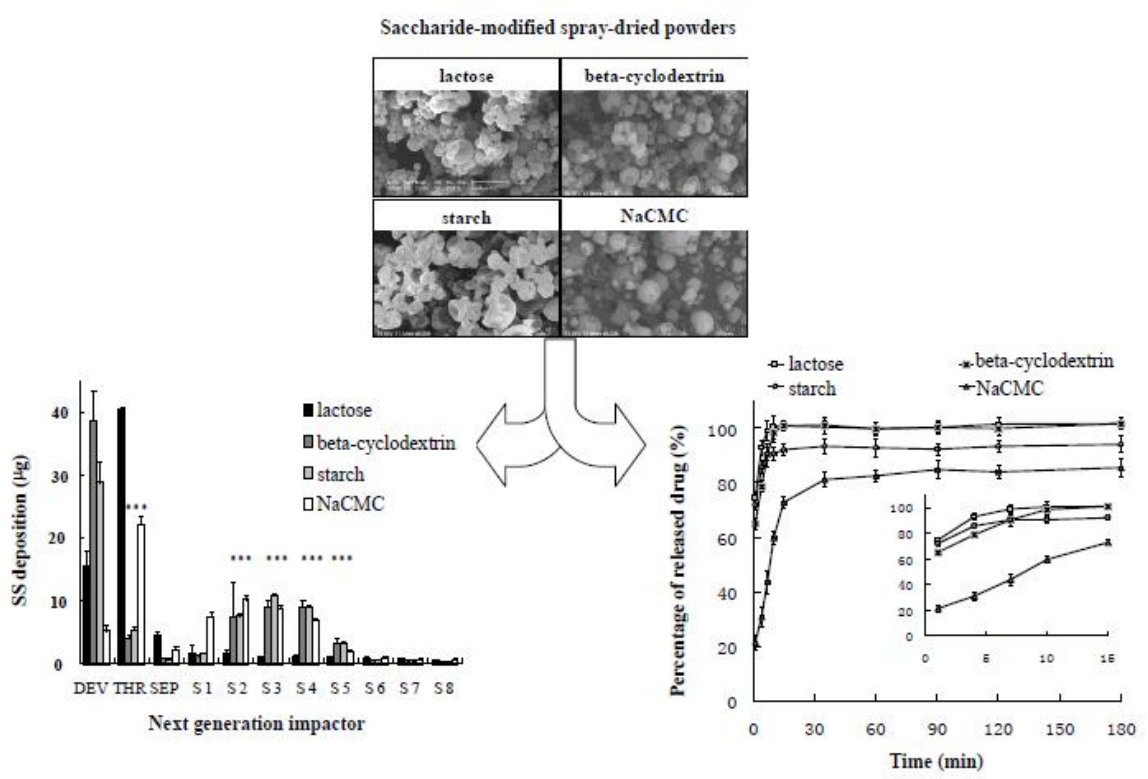


Highlights

- $\quad$ Di-, oligo- and poly-saccharides are used to develop novel inhalable powders.

- Polysaccharide-based powders exhibit improved aerosolisation characteristics.

- They also demonstrate sustained drug release profiles in dissolution testing.

- Opportunity to develop respirable powders that offer controlled drug release.

- Potential benefit in management of local (e.g. asthma) and systemic (e.g. diabetes) conditions. 